\title{
Impact of periampullary diverticulum on biliary cannulation and ERCP outcomes: A single-center prospective study
}

Fatema Tabak, Guo-Zhong Ji, Lin Miao

Institute of Digestive Endoscopy and Medical Center for Digestive Disease, Second Affiliated Hospital of Nanjing Medical University, Nanjing, 210011, Jiangsu Province, China

Correspondence to Lin Miao, MD, Ph.D., Director and Professor, Medical Centre for Digestive Diseases, Second Affiliated Hospital of Nanjing Medical University, China. linmiao@njmu.edu.cn Telephone: +86-25-58509932

\begin{abstract}
AIM

This study aimed to investigate the association between periampullary diverticulum (PAD) and difficult biliary cannulation, as well as to evaluate the impact of different types of PAD on the cannulation success rate and adverse events.
\end{abstract}

\section{METHODS}

A total of 636 patients who underwent endoscopic retrograde cholangiopancreatography (ERCP) during the study period were prospectively studied and divided into two groups based on the presence or absence of PAD. In group A, 126 patients had PAD compared with 510 patients in group B without PAD. The primary outcome measurements were ERCP procedures time, selective cannulation techniques, and cannulation difficulty in addition to cannulation success rate and ERCP-related adverse events. The difficult cannulation was analyzed using logistic regression considering age, co-morbidities, the presence of PAD types, and indications as independent factors.

\section{RESULTS}

The average cohort age was $65.30 \pm 16.67$ years, and 52.7\% were male. Significant higher rates of choledocholithiasis, cholangitis, and biliary pancreatitis were reported in the group of PAD $(\mathrm{p}<0.05)$. Successful selective cannulation was achieved in $97.6 \%$ in group A and $95.3 \%$ in group B ( $>0.05)$. The cannulation time was significantly longer in the presence of PAD (5.1 min, vs. $4.09 \mathrm{~min}, \mathrm{p}<0.05)$. There was no significant difference in the rate of overall adverse events and post ERCP pancreatic PEP. 


\section{CONCLUSION}

The presence of PAD did not affect the duration or success of the ERCP procedure. Furthermore, it was associated with longer cannulation time and increase in the cannulation difficulty, especially with PAD type 1.

Key Words: Endoscopic retrograde cholangiopancreatography, Periampullary diverticulum, Difficult cannulation, Biliary cannulation, Cannulation techniques, Adverse events

Core tip: Periampullary diverticulum (PAD) is frequently come upon during ERCP, especially in elderly patients. Several studies described the effect of PAD on the ERCP outcomes. However, less is known about the role of PAD in biliary cannulation difficulty. This study aims to clarify the association of PAD and difficult cannulation, as well as to evaluate the impact of different types of $\mathrm{PAD}$ on the cannulation success rate and the adverse events.

\section{INTRODUCTION}

Increasing the life expectancy and application of ERCP in the elderly population comes with a higher rate of the periampullary diverticulum (PAD) [1]-[3]. The incidence of PAD varies according to different diagnostic approaches and the age of the population; it is observed in 5$30 \%$ of ERCP cases [4], [5]. Although PAD is an asymptomatic finding in ERCP patients, it could be associated with technical difficulties in the biliary cannulation and higher complication expectations [6]-[9].

PAD is defined endoscopically as an extraluminal mucosal outpouching of the periampullary region of the duodenum [3], [5]. It usually arises within a radius of 2-3 cm from the ampulla of Vater, and it is classified into three types according to the position of the major papilla from the endoscopic view. The first type refers to the case where the major papilla is located inside of the diverticula; the second type refers to the case where the major papilla is located at the edge of the diverticula while the third type refers to the case where the major papilla is located outside of the diverticula [1], [3], [8].

There are conflicting data about the influence of PAD presence on the technical success rates and safety outcomes of ERCP. The first group of studies published in the 1980s and 1990s suggested a significantly higher rate of cannulation's failure in patients with PAD, prolonged procedure 
time, and an increase in adverse events' rates [10], [11]. The second group of studies showed that there is no significant difference in the cannulation procedure success in case of presence or absence of PAD [12]-[14]. Moreover, recent prospective studies did not reveal any significant difference in either overall adverse events or a specific event, especially PEP [15]-[17].

Different techniques are reported in the literature regarding cannulation of the papilla in the presence of PAD [4], [5], [18]. However, more studies should be performed to evaluate the safety and efficacy of techniques used for biliary cannulation with PAD.

This prospective study aimed to investigate the association of PAD and pancreaticobiliary diseases, as well as to evaluate the impact of different types of PAD on cannulation success rate, the difficulty of biliary cannulation, and adverse events.

\section{MATERIALS AND METHODS}

\section{Data Source and Participants}

This study was performed in the Institute of Digestive Endoscopy, Second Affiliated Hospital of Nanjing Medical University between July 2016 and July 2018. Patients who underwent ERCP for follow up, stent removing, or taking a biopsy were excluded. The study protocol was registered and approved by the institutional review board of the Second Affiliated Hospital of Nanjing Medical University.

\section{Data Type}

The data are collected using a designed form that reported the clinical features of each patient.

Data describing the patients' characteristics such as age, gender, indications, comorbid diseases, performed therapeutic procedures, procedure outcomes, and ERCP related adverse events were analyzed.

We classified the comorbid diseases as hypertension, cardiac diseases (ischemic heart diseases, heart failure), neurology (cerebrovascular diseases, dementia), hepatic diseases, diabetes mellitus, malignancy, renal diseases, and chronic pulmonary diseases. Also, the Charlson Comorbidities Index (CCI) score was calculated for each patient. 
Indications were organized as choledocholithiasis with/without biliary pancreatitis, cholangitis, chronic pancreatitis, benign strictures, known/suspected cholangiocarcinoma, ampullary, and pancreatic carcinoma.

The ERCP procedure's success rate was defined according to the achievement of the preprocedural goal [13]. Adverse events included post-ERCP pancreatitis, perforations, cholangitis, and post-procedural bleeding evidenced by a drop-in hemoglobin $>2 \mathrm{~g} / \mathrm{dl}$. All adverse events were defined according to published criteria [14].

\section{Diagnostic Procedure}

After obtaining written informed consent, all the ERCP procedures were performed by experienced endoscopists in our center using side-view duodenoscope. For PEP prevention, prophylactic octreotide dose was administered to all patients before ERCP. Patients were monitored continuously during ERCP using a pulse oximeter and electrocardiography monitoring. Supplementary oxygen was provided during conscious sedation.

Cannulation performed mainly using guidewire cannulation. The secondary techniques for difficult access cases were needle-knife fistulotomy, pancreatic stent placement, and transpancreatic biliary sphincterotomy. In recent studies, cannulation is defined as difficult if one of these conditions is satisfied; the cannulation procedure time is more than 10 minutes; the cannulation attempts on the papilla are more than ten; the pancreatic duct was cannulated more than twice [4], [19].

\section{Data Analysis}

Differences among different patient cohorts were determined by using Fisher's exact test for categorical variables, and non-categorical variables with the Mann-Whitney U test. Both univariate and multivariate regression models were performed with significant variables $(\mathrm{p}<0.05)$. Variables of potential significance $(\mathrm{p}<0.10)$ were entered the multivariate analysis (logistic regression analysis, enter method). Odds ratios and adjusted odds ratios were reported for each variable. All statistical analyses were performed using SPSS Statistics version 20 for Windows. 


\section{RESULTS}

\section{Study Population}

A total of 952 patients who underwent ERCP during the study period have entered the study (Fig. 1). Of these, 316 patients did not meet the requirements of the study and were excluded from the analysis. We excluded the patients of follow-up (166), removing stents (114), and taking a biopsy (36). Accordingly, only 636 patients were analyzed and divided based on PAD presence into two groups; the first group A included patients with PAD; 126 patients of overall cases, the second group B included 510 patients without PAD (Table 1). Later, the PAD patients were filtered based on the types of PAD; 93 patients had PAD type 3; 18 patients had type 2, and 15 patients had type 1 (see Table 2 ).

\section{Patient Characteristics}

Based on the PAD's presence, $19.8 \%$ of patients were considered in the PAD group (group A) with an average age of $72.63 \pm 12.12$ (see Table 1). The control group included 510 patients with an average age of $63.47 \pm 17.15$. A single diverticulum was found in $84.2 \%$ of patients with PAD, $15.8 \%$ had two diverticulum or more. There was no significant difference in patients' gender in both groups, with a male percentage $(57.9 \%$ vs. $51.4 \%, \mathrm{p}=0.175)$. The presence of PAD was not associated with differences in the overall comorbidities $(\mathrm{p}=0.078)$ and the proportion of patients with $\mathrm{CCI} \geq 2(23.8 \%$ vs. $19.8 \%, \mathrm{p}=0.300)$. 


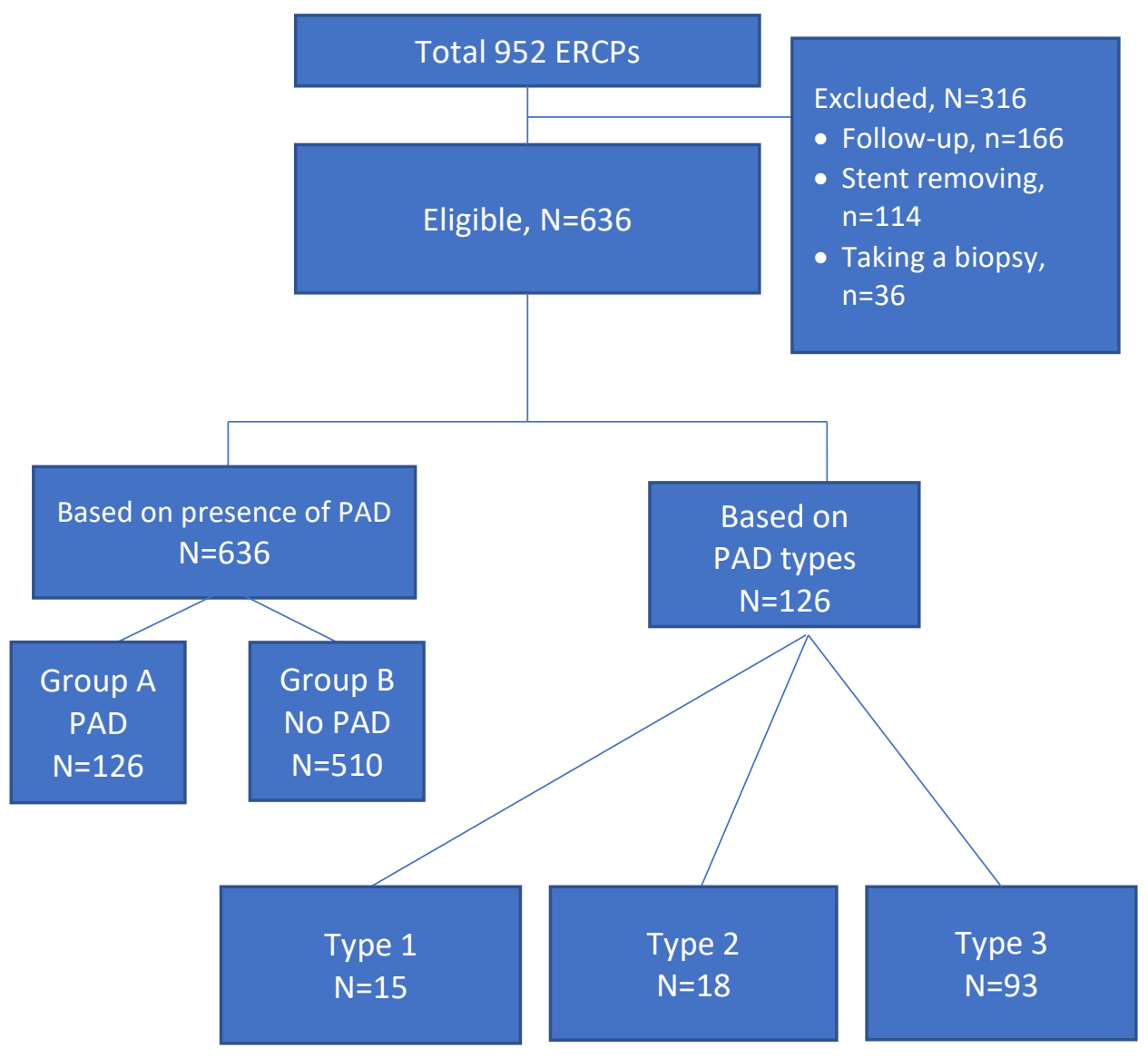

Figure 1 ERCP sample breakdown

In the PAD patients' group, significantly higher rates of biliary stones $(88.1 \%$ vs. $79.4 \%$, $\mathrm{p}=0.044)$, biliary pancreatitis $(10.3 \%$ vs. $4.5 \%, \mathrm{p}=0.018)$ and cholangitis $(14.3 \%$ vs. $7.4 \%$ $\mathrm{p}=0.023$ ) were noted compared with the control group B. Furthermore, patients with PAD had a lower proportion of benign and malignant biliary strictures; cholangiocarcinoma (3.2\% vs. 4.7\%, $\mathrm{p}=0.629)$; pancreatic cancer $(3.2 \%$ vs. $3.9 \%, \mathrm{p}=0.800)$, and a significant lower rate of ampullary carcinoma ( $0 \%$ vs. $3.9 \%, \mathrm{p}=0.020)$.

The presence of PAD was associated with significantly longer cannulation time than that in the control group. The mean cannulation time in group A was 5.1 \pm 8.9 minutes, with a significant difference between the two groups $(\mathrm{p}=0.013)$. Considering the cannulation difficulty grading, the proportion of difficult cannulation was significantly higher in group A $(30.9 \%$ vs. 20\%, $\mathrm{p}=0.010$ ). However, the two groups had similar procedure time, and no difference was found in the ERCP cannulation success rate $(97.6 \%$ vs. $95.3 \%, \mathrm{p}=0.506)$. 
Successful cannulation was achieved using a guidewire with sphincterotomy as the primary biliary and the most common cannulation technique in both groups $(73.8 \%$ vs. $75.3 \%, \mathrm{p}=0.577)$. On the other hand, the presence of PAD was associated with a higher rate of using needle-knife fistulotomy $(19.8 \%$ vs. $13.9 \%, \mathrm{p}=0.089)$ and trans-pancreatic biliary sphincterotomy $(8.7 \%$ vs. $6.3 \%, \mathrm{p}=0.328$ ). However, no significant differences have been noticed in the rates of pancreatic stent placement $(13.5 \%$ vs. $18.2 \%, \mathrm{p}=0.237)$ and the used cannulation techniques between the two groups.

There was no significant difference between the two groups in the adverse event rate, especially post-ERCP pancreatitis ( $4.8 \%$ vs. $5.1 \% \mathrm{p}=0.535)$ and perforation $(0 \%$ vs. $0.6 \%, \mathrm{p}=0.511)$. Also, no significant difference was found in Post-ERCP bleeding rate, although there was a higher rate of bleeding with the presence of PAD (3.2\% vs. $1.8 \% \mathrm{p}=0.304)$.

Table 1. Characteristics' summary of patients in groups A and B

\begin{tabular}{|c|c|c|c|c|}
\hline Parameter & $\begin{array}{l}\text { Overall } \\
(n=636)\end{array}$ & $\begin{array}{l}\text { Group A } \\
\text { PAD } \\
(n=126)\end{array}$ & $\begin{array}{l}\text { Group B } \\
\text { Control } \\
(n=510)\end{array}$ & p-value \\
\hline $\begin{array}{l}\text { Age }[\text { mean } \\
\text { deviation] }(y)\end{array}$ & $65.30 \pm 16.67$ & $72.63 \pm 12.12$ & $63.47 \pm 17.15$ & $0.963^{\mathrm{a}}$ \\
\hline Charlson score [median (IQR)] & $0(0,1)$ & $0(0,1)$ & $0(0,1)$ & $0.078^{\mathrm{a}}$ \\
\hline Charlson score $\geq 2$ & $20.6 \%(131)$ & $23.8 \%(30)$ & $19.8 \%(101)$ & $0.300^{\mathrm{b}}$ \\
\hline $\begin{array}{l}\text { ERCP procedure time (mean) } \\
\text { (min) }\end{array}$ & $36.07 \pm 19.74$ & $38.17 \pm 22.4$ & $35.54 \pm 19$ & $0.197^{\mathrm{a}}$ \\
\hline Cannulation time (mean) (min) & $4.29 \pm 7.24$ & $5.1 \pm 8.9$ & $4.09 \pm 7.15$ & $0.013^{\mathrm{a}}$ \\
\hline Male & $52.7 \%(335)$ & $57.9 \%(73)$ & $51.4 \%(262)$ & $0.175^{\mathrm{b}}$ \\
\hline Cannulation success rate & $95.7 \%(609)$ & $97.6 \%(123)$ & $95.3 \%(486)$ & $0.506^{\mathrm{b}}$ \\
\hline \multicolumn{5}{|l|}{ Indications } \\
\hline Biliary stones & $81.1 \%(516)$ & $88.1 \%(111)$ & $79.4 \%(405)$ & $0.044^{\mathrm{b}}$ \\
\hline Benign strictures & $13.1 \%(83)$ & $8.7 \%(11)$ & $14.1 \%(72)$ & $0.099^{b}$ \\
\hline Cholangiocarcinoma & $4.4 \%(28)$ & $3.2 \%(4)$ & $4.7 \%(24)$ & $0.629^{\mathrm{b}}$ \\
\hline Cholangitis & $8.8 \%(56)$ & $14.3 \%(18)$ & $7.4 \%(38)$ & $0.023^{b}$ \\
\hline Biliary pancreatitis & $5.7 \%(36)$ & $10.3 \%(13)$ & $4.5 \%(23)$ & $0.018^{\mathrm{b}}$ \\
\hline Chronic pancreatitis & $1.3 \%(8)$ & $0.8 \%(1)$ & $1.4 \%(7)$ & $0.502^{b}$ \\
\hline Ampullary carcinoma & $3.1 \%(20)$ & $0 \%(0)$ & $3.9 \%(20)$ & $0.020^{\mathrm{b}}$ \\
\hline Pancreatic cancer & $3.8 \%(24)$ & $3.2 \%(4)$ & $3.9 \%(20)$ & $0.800^{b}$ \\
\hline $\begin{array}{l}\text { Difficult cannulation } \\
\text { Adverse events }\end{array}$ & $22.2 \%(141)$ & $30.9 \%(39)$ & $20 \%(102)$ & $0.010^{\mathrm{b}}$ \\
\hline PEP & $5 \%(32)$ & $4.8 \%(6)$ & $5.1 \%(26)$ & $0.535^{b}$ \\
\hline Perforation & $0.5 \%(3)$ & $0 \%(0)$ & $0.6 \%(3)$ & $0.511^{\mathrm{b}}$ \\
\hline Bleeding & $2 \%(13)$ & $3.2 \%(4)$ & $1.8 \%(9)$ & $0.304^{b}$ \\
\hline Cholangitis & $0.6 \%(4)$ & $0 \%(0)$ & $0.8 \%(4)$ & $0.589^{b}$ \\
\hline
\end{tabular}




\begin{tabular}{|c|c|c|c|c|}
\hline Cardiopulmonary & $0.6 \%(4)$ & $0 \%(0)$ & $0.8 \%(4)$ & $0.589^{\mathrm{b}}$ \\
\hline Pancreatic stent & $17.3 \%(110)$ & $13.5 \%(17)$ & $18.2 \%(93)$ & $0.237^{b}$ \\
\hline \multicolumn{5}{|l|}{ Cannulation techniques } \\
\hline Guidewire & $75 \%(477)$ & $73.8 \%(93)$ & $75.3 \%(384)$ & $0.577^{\mathrm{b}}$ \\
\hline Needle-knife fistulotomy & $15.1 \%(96)$ & $19.8 \%(25)$ & $13.9 \%(71)$ & $0.089^{b}$ \\
\hline $\begin{array}{l}\text { Trans-pancreatic biliary } \\
\text { sphincterotomy }\end{array}$ & $6.8 \%(43)$ & $8.7 \%(11)$ & $6.3 \%(32)$ & $0.328^{\mathrm{b}}$ \\
\hline
\end{tabular}

IQR, interquartile range.

${ }^{a}$ Independent sample Mann-Whitney U-test.

bisher's exact test.

In this study, we revealed clinical characteristics according to the PAD subtypes. The most frequent diagnosed subtype of PAD was type 3 , with $73.8 \%$ of overall PAD cases, followed by type $2(14.3 \%)$, and type $1(11.9 \%)$. The correlation between PAD subtypes and clinical characteristics was reported in Table 2.

We noted that patients with type 2 had a significantly higher rate of biliary pancreatitis as an indication of ERCP $(6.7 \%$ vs. $27.8 \%$ vs. $7.5 \%$, p $<0.001)$. In addition, cholangitis was more common in patients with type $1(26.7 \%$ vs. $11.1 \%$ vs. $12.9 \%$, $\mathrm{p}=0.030)$.

Patients with type 1 had a significantly longer procedure time $(\mathrm{p}=0.032)$, cannulation time $(\mathrm{p}=0.001)$, and a higher rate of cannulation difficulty $(\mathrm{p}<0.001)$.

Table 2. Summary of essential characteristics of patients considering PAD types

\begin{tabular}{|c|c|c|c|c|}
\hline Parameter & $\begin{array}{l}\text { Type } 1 \\
(n=15)\end{array}$ & $\begin{array}{l}\text { Type } 2 \\
(n=18)\end{array}$ & $\begin{array}{l}\text { Type } 3 \\
(n=93)\end{array}$ & p-value \\
\hline $\begin{array}{l}\text { Age [mean } \pm \\
\text { deviation] }(y)\end{array}$ & $70.07 \pm 11.36$ & $71.17 \pm 14.26$ & $73.33 \pm 11.85$ & $0.566^{\mathrm{a}}$ \\
\hline Charlson score [median (IQR)] & $0(0,0.5)$ & $0(0,1)$ & $1(0,2)$ & $0.065^{\mathrm{a}}$ \\
\hline Charlson score $\geq 2$ & $13.3 \%(2)$ & $16.7 \%(3)$ & $26.9 \%(25)$ & $0.363^{b}$ \\
\hline $\begin{array}{l}\text { ERCP procedure time (mean) } \\
\text { (min) }\end{array}$ & $52.53 \pm 27.5$ & $36.22 \pm 15.8$ & $36.23 \pm 21.9$ & $0.032^{\mathrm{a}}$ \\
\hline Cannulation time (mean) (min) & $8.8 \pm 11.2$ & $4.5 \pm 8.8$ & $4.6 \pm 7.7$ & $0.001^{\mathrm{a}}$ \\
\hline Male & $46.7 \%(7)$ & $55.6 \%(10)$ & $60.2 \%(56)$ & $0.417^{\mathrm{b}}$ \\
\hline ERCP success rate & $100 \%(15)$ & $94.4 \%(17)$ & $97.8 \%(91)$ & $0.733^{\mathrm{b}}$ \\
\hline \multicolumn{5}{|l|}{ Indications } \\
\hline Biliary stones & $80 \%(12)$ & $100 \%(18)$ & $87.1 \%(81)$ & $0.089^{\mathrm{b}}$ \\
\hline Benign strictures & $6.7 \%(1)$ & $0 \%(0)$ & $10.7 \%(10)$ & $0.230^{\mathrm{b}}$ \\
\hline Cholangiocarcinoma & $6.7 \%(1)$ & $0 \%(0)$ & $3.2 \%(3)$ & $0.692^{b}$ \\
\hline Cholangitis & $26.7 \%(4)$ & $11.1 \%(2)$ & $12.9 \%(12)$ & $0.030^{\mathrm{b}}$ \\
\hline Biliary pancreatitis & $6.7 \%(1)$ & $27.8 \%(5)$ & $7.5 \%(7)$ & $<0.001^{\mathrm{b}}$ \\
\hline Chronic pancreatitis & $0 \%(0)$ & $0 \%(0)$ & $1.1 \%(1)$ & $0.917^{\mathrm{b}}$ \\
\hline
\end{tabular}




\begin{tabular}{|c|c|c|c|c|}
\hline Ampullary carcinoma & $0 \%(0)$ & $0 \%(0)$ & $0 \%(0)$ & - \\
\hline Pancreatic cancer & $6.7 \%(1)$ & $0 \%(0)$ & $3.2 \%(3)$ & $0.761^{b}$ \\
\hline Difficult cannulation & $66.7 \%(10)$ & $22.2 \%(4)$ & $26.9 \%(25)$ & $<0.001^{\mathrm{b}}$ \\
\hline \multicolumn{5}{|l|}{ Adverse events } \\
\hline PEP 8 & $13.3 \%(2)$ & $5.6 \%(1)$ & $3.2 \%(3)$ & $0.424^{b}$ \\
\hline Perforation 2 & $0 \%(0)$ & $0 \%(0)$ & $0 \%(0)$ & - \\
\hline Bleeding 3 & $0 \%(0)$ & $0 \%(0)$ & $4.3 \%(4)$ & $0.363^{b}$ \\
\hline Cholangitis 4 & $0 \%(0)$ & $0 \%(0)$ & $0 \%(0)$ & - \\
\hline Cardiopulmonary 6 & $0 \%(0)$ & $0 \%(0)$ & $0 \%(0)$ & - \\
\hline Pancreatic stent & $20 \%(3)$ & $16.7 \%(3)$ & $11.8 \%(11)$ & $0.481^{\mathrm{b}}$ \\
\hline \multicolumn{5}{|l|}{ Cannulation techniques } \\
\hline Guidewire & $66.7 \%(10)$ & $86.7 \%(13)$ & $75.3 \%(70)$ & $0.835^{\mathrm{b}}$ \\
\hline Precut & $33.3 \%(5)$ & $16.7 \%(3)$ & $18.3 \%(17)$ & $0.171^{\mathrm{b}}$ \\
\hline $\begin{array}{l}\text { Trans-pancreatic } \\
\text { sphincterotomy }\end{array}$ & $13.3 \%(2)$ & $16.7 \%(3)$ & $6.4 \%(6)$ & $0.268^{b}$ \\
\hline
\end{tabular}

IQR, interquartile range.

${ }^{a}$ Independent sample Mann-Whitney U-test.

${ }^{b}$ Fisher's exact test.

The difficult cannulation multivariate analysis model was created considering age, male gender, $\mathrm{CCI} \geq 2$, indications, and PAD types as independent variables (Table 3). Logistic regression showed that age $\geq 65$, male gender, and $\mathrm{CCI} \geq 2$ was not associated with increased cannulation difficulty. Regarding the impact of the three types of PAD, patients with type 1 (adjusted odds ratio $[A O R]=11.20 ; 95 \%$ confidence interval $[\mathrm{CI}]=3.5,35.87 ; \mathrm{p}<0.001)$ were the most likely to have cannulation difficulty when adjusted for the other variables. Biliary stones (AOR $=0.20$; 95\% $\mathrm{CI}=0.1,0.388 ; \mathrm{p}<0.001)$ and cholangitis $(\mathrm{AOR}=0.50 ; 95 \% \mathrm{CI}=0.223,1.132 ; \mathrm{p}=0.041)$ were more likely to be related to difficult cannulation when adjusted for the other variables.

Table 3. Multivariate analysis of difficult cannulation considering age, gender, diverticulum types, indications, and CCI

\begin{tabular}{llllll}
\hline & & $\begin{array}{l}\text { Adjusted odds } \\
\text { ratio }\end{array}$ & $\begin{array}{l}\mathbf{9 5 \%} \\
\text { interval } \\
\text { Lower }\end{array}$ & $\begin{array}{l}\text { Confidence } \\
\text { Upper }\end{array}$ & p-value \\
\hline $\begin{array}{l}\text { Difficult } \\
\text { cannulation }\end{array}$ & & & & & \\
\hline Age & $\geq 65$ & 0.775 & 0.508 & 1.185 & 0.239 \\
\hline Gender & Male & 0.956 & 0.641 & 1.426 & 0.825 \\
\hline Diverticulum & & & & & \\
& Type 1 & 11.20 & 3.50 & 35.87 & $<0.001$ \\
& Type 2 & 1.68 & 0.53 & 5.32 & 0.373 \\
& Type 3 & 1.82 & 1.05 & 3.14 & 0.098 \\
\hline
\end{tabular}

Indications 


\begin{tabular}{|c|c|c|c|c|c|}
\hline & Cholangitis & 0.50 & 0.223 & 1.132 & 0.041 \\
\hline & Stones & 0.20 & 0.100 & 0.388 & $<0.001$ \\
\hline & Benign strictures & 0.67 & 0.332 & 1.354 & 0.265 \\
\hline & $\begin{array}{l}\text { Pancreatobilliary } \\
\text { tumors }\end{array}$ & 1.16 & 0.574 & 4.760 & 0.875 \\
\hline CCI & $\mathrm{CCI} \geq 2$ & 1.221 & 0.741 & 2.010 & 0.433 \\
\hline
\end{tabular}

\section{Risk Factors of Adverse Events}

In the second multivariate model, we studied the factors that were found to be related to the presence of PAD, as it is shown in Table 4. Logistic regression showed that factor of age $\geq 65$ (AOR=3.281; 95\% $\mathrm{CI}=2.068,5.206 ; \mathrm{p}<0.001)$, difficult cannulation $(\mathrm{AOR}=2.257 ; 95 \%$ $\mathrm{CI}=1.248,4.083 ; \mathrm{p}=0.007$ ), patients with cholangitis $(\mathrm{AOR}=2.006 ; 95 \% \mathrm{CI}=1.094,3.9$; $\mathrm{p}=0.025)$, biliary stones $(\mathrm{AOR}=2.222 ; 95 \% \mathrm{CI}=1.193,4.140 ; \mathrm{p}=0.012)$ and biliary pancreatitis $(\mathrm{AOR}=2.498 ; 95 \% \mathrm{CI}=1.168,5.344 ; \mathrm{p}=0.018)$ were strongly associated with presence of PAD.

Table 4. Multivariate analysis of PAD considering age, difficult cannulation, and indications

\begin{tabular}{llllll}
\hline & & $\begin{array}{l}\text { Adjusted } \begin{array}{c}\text { odds } \\
\text { ratio }\end{array} \\
\text { PAD }\end{array}$ & $\begin{array}{l}\text { 95\% } \\
\text { interval } \\
\text { Lower }\end{array}$ & $\begin{array}{l}\text { Confidence } \\
\text { Upper }\end{array}$ & p-value \\
\hline Age & More65 & & & & \\
$\begin{array}{l}\text { Difficult } \\
\text { cannulation }\end{array}$ & & 3.281 & 2.068 & 5.206 & $<0.001$ \\
$\begin{array}{l}\text { Indications } \\
\end{array}$ & 2.257 & 1.248 & 4.083 & 0.007 \\
& Cholangitis & & & & \\
& Stones & 2.066 & 1.094 & 3.900 & 0.025 \\
& Gallstone pancreatitis & 2.498 & 1.193 & 4.140 & 0.012 \\
& & & 1.168 & 5.344 & 0.018 \\
\hline
\end{tabular}

\section{DISCUSSION}

The current study focused on the association of different types of periampullary diverticulum with ERCP cannulation success. Also, it studied the difficulty and safety of papillary cannulation in the presence of PAD. This stricture was found in $19.8 \%$ of our participants, which was acceptable comparing with previous reports (3\%-25\%). The detailed description of the PAD showed that type 3 was the most common subgroup, followed by type 1 and type 2 . Regarding overall comorbidities, using a cutoff of $\mathrm{CCI} \geq 2$, no significant difference was seen between the two groups.

Several studies have considered PAD as an essential risk factor of biliary stones formation [20]- 
[24], which is also suggested by our results. We noted that almost all PAD patients with type 1 have biliary stones, which were more common compared with types 2 and 3, although it did not reach a statistical difference. A possible explanation for the association between PAD and choledocholithiasis can be related to the spasm of Oddi sphincter caused by diverticula. This dysfunction in the sphincter of Oddi causes increasing in biliary tract pressure and intestinal content reflux leading to biliary stone formation. Besides, the possibility of distal CBD part compression could cause functional biliary stasis, which may produce cholangitis and incidence of biliary stones. Thus, our study also supports the fact that cholangitis and biliary pancreatitis are more common in the presence of PAD.

Besides, we found a lower proportion of periampullary malignancy, especially ampullary carcinoma, in group A compared with group B, and a negative correlation between malignancy and PAD. This finding is supported by prior studies that found that neoplastic lesions as colorectal and periampullary carcinoma were less common in patients with the diverticular disease [25], [26].

Regarding ERCP outcomes, previous studies have shown different results regarding the procedure success rates and visualization rates of main biliary structures in patients with PAD. The experience of the endoscopists, using different cannulation techniques, patients' characteristics, and study design can be factors that reveal various findings regarding cannulation success and difficulty in patients with PAD [11]-[14], [17]. In our study, we did not observe significant differences in ERCP success rate and procedure duration between the two groups, although the PAD group was more likely to have cannulation difficulty and longer cannulation time (see Fig 2). Furthermore, cannulation in PAD patients with type 1, in which papilla is located inside the diverticula, was more challenging and has been associated more frequently with cannulation difficulty. 


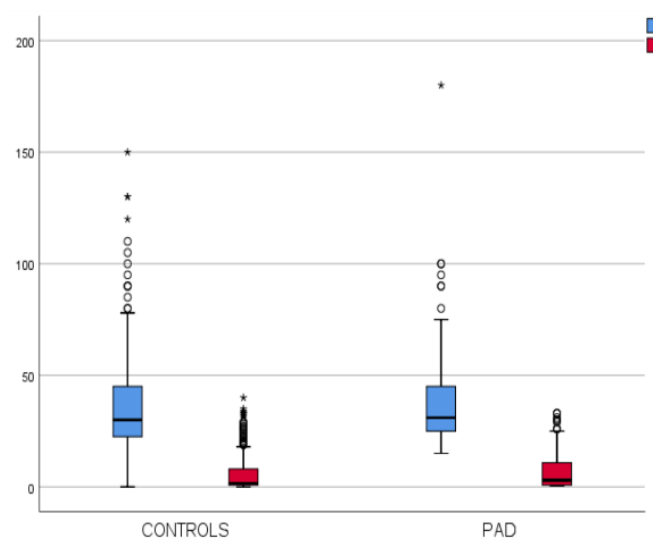

(a)

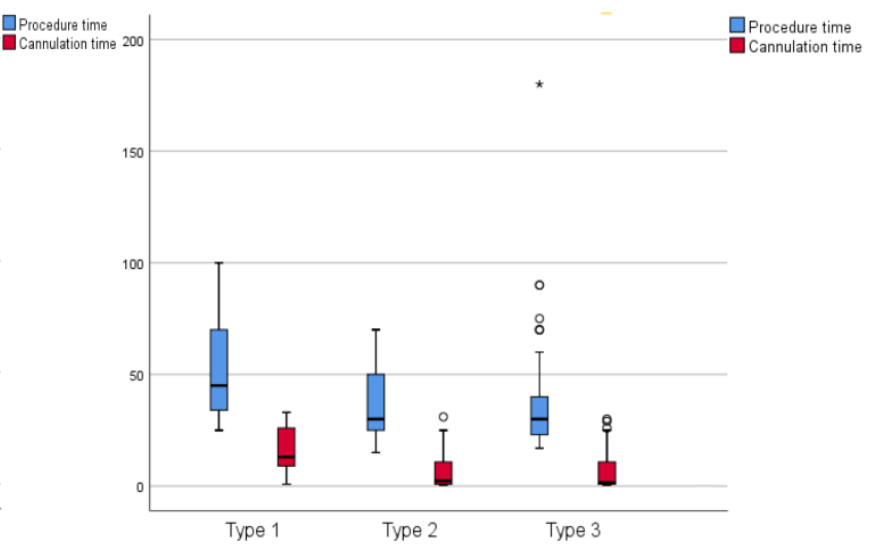

(b)

Figure 2 Procedure time and cannulation time. (a) Patients with PAD versus controls; (b) Patients with type 1 PAD versus those with type 2 and type 3.

In the literature, several retrospective studies described different cannulation techniques in the presence of a PAD [27]-[31]. The most frequently described techniques in those studies were pancreatic duct stent placement, followed by needle-knife fistulotomy, and cap-assisted forwardviewing endoscopy.

Our study had prospectively compared the efficacy of access common biliary duct by different methods in the presence of PAD. All cannulation techniques were effective in achieving successful biliary access in the two groups without significant differences in overall adverse events. Standard cannulation using guidewire cannulation with sphincterotomy was the most frequent cannulation technique in both groups. Needle knife fistulotomy with or without pancreatic duct stent placement was a suitable option for difficult cannulation cases and more frequent in the PAD group, especially in type 1, without significant differences. Trans-pancreatic biliary sphincterotomy was also available to cannulate the papilla in the presence of PAD, and patients with type 2 had a higher frequency to use this technique.

Regarding finding the factors that affect cannulation difficulty, using a multivariate analysis model, we did not find any increase in the odds of cannulation difficulty with advanced age, high CCI, and male gender. However, an increased odds of difficult cannulation was noted with PAD type $1(\mathrm{AOR}=11.2)$ and with the indication of cholangitis $(\mathrm{AOR}=0.50)$ and choledocholithiasis $(\mathrm{AOR}=0.20)$. 
In the relation between the presence of PAD and adverse events, different results have been reported according to older and more recent literature [15], [16], [32]. Our study, as well as most recent studies, had not found any significant difference in overall adverse events or a specific event, especially PEP [4], [15]. However, we found that patients of type 1 had a higher frequency of PEP than patients with type 2 or type 3 . That is related to the specific location of type1, which may cause pancreatic duct compression and pancreatitis as a result. In addition, a higher rate of bleeding was related to patients with type 3 .

The main strength of this study is its prospective nature, and to the best of our knowledge, there are fewer studies that focused on difficult cannulation and its relation with PAD. There are few limitations in this study; first is that the data were collected at a single center; second is the rarity of specific adverse events though our sample size patients were reasonable.

In conclusion, this study has shown that although difficult cannulation ERCP is more common in patients with PAD, procedure time and successful cannulation rates are similar to those without PAD. As well as using different techniques is well tolerated with a similar rate of post ERCP pancreatitis in patients with and without PAD. Interestingly, our study demonstrated that the presence of PAD type 1, biliary stones, and cholangitis are correlated with difficult cannulation.

\section{Availability of data and materials}

The dataset of this study is available from the corresponding author on a reasonable request.

\section{Clinical Trial Study Registration}

This study is approved by Nanjing Medical University and registered at ClinicalTrial.gov PRS with ID /NCT03771547/.

\section{Authors contributions}

Data curation, Fatema Tabak; Formal analysis, Fatema Tabak; Project administration, GuoZhong Ji and Lin Miao; Resources, Fatema Tabak; Supervision, Guo-Zhong Ji and Lin Miao; Writing - original draft, Fatema Tabak; Writing - review \& editing, Fatema Tabak, Guo-Zhong $\mathrm{Ji}$, and Lin Miao.

\section{Funding}

This research received no external funding. 


\section{Conflicts of interests}

The authors declare no conflict of interest.

\section{References}

[1] J. H. Siegel and F. E. Kasmin, "Biliary tract diseases in the elderly: Management and outcomes," Gut, vol. 41, no. 4, pp. 433-435, 1997.

[2] P. B. Cotton, "Endoscopic management of bile duct stones; (Apples and oranges)," Gut, vol. 25, no. 6. pp. 587-597, 1984.

[3] D. N. Lobo, T. W. Balfour, S. Y. Iftikhar, and B. J. Rowlands, "Periampullary diverticula and pancreaticobiliary disease," British Journal of Surgery. 1999.

[4] P. A. Testoni et al., "Papillary cannulation and sphincterotomy techniques at ERCP: European Society of Gastrointestinal Endoscopy (ESGE) Clinical Guideline," Endoscopy, vol. 48, no. 7. pp. 657-683, 2016.

[5] N. Egawa, H. Anjiki, K. Takuma, and T. Kamisawa, "Juxtapapillary Duodenal Diverticula and Pancreatobiliary Disease," Digestive Surgery, vol. 27, no. 2, pp. 105-109, 2010.

[6] B. Ozogul, G. Ozturk, A. Kisaoglu, B. Aydinli, M. Yildirgan, and S. S. Atamanalp, "The clinical importance of different localizations of the papilla associated with juxtapapillary duodenal diverticula," Canadian Journal of Surgery, vol. 57, no. 5, pp. 337-341, 2014.

[7] F. Tabak et al., "ERCP in Super-Aged Patients Considering Difficult Cannulation: Challenges and Adverse Events," Preprints, 2019.

[8] J. Boix, V. Lorenzo-Zúñiga, F. Añaños, E. Domènech, R. M. Morillas, and M. A. Gassull, "Impact of periampullary duodenal diverticula at endoscopic retrograde cholangiopancreatography: A proposed classification of periampullary duodenal diverticula," Surgical Laparoscopy, Endoscopy and Percutaneous Techniques, vol. 16, no. 4, pp. 208-211, 2006.

[9] Q. Chen, P. Jin, X. Ji, H. Du, and J. Lu, "Management of difficult or failed biliary access in initial ERCP: A review of current literature," Clinics and Research in Hepatology and Gastroenterology. 2019.

[10] D. Vaira et al., "Is duodenal diverticulum a risk factor for sphincterotomy?," Gut, 1989.

[11] A. P. Kirk and J. A. Summerfield, "Incidence and significance of juxtapapillary diverticula at endoscopic retrograde cholangiopancreatography," Digestion, 1980.

[12] V. Panteris, A. Vezakis, G. Filippou, D. Filippou, D. Karamanolis, and S. Rizos, "Influence of juxtapapillary diverticula on the success or difficulty of cannulation and complication rate," Gastrointestinal Endoscopy, vol. 68, no. 5, pp. 903-910, 2008. 
[13] L. Chen, L. Xia, Y. Lu, L. Bie, and B. Gong, "Influence of periampullary diverticulum on the occurrence of pancreaticobiliary diseases and outcomes of endoscopic retrograde cholangiopancreatography," European Journal of Gastroenterology and Hepatology, 2017.

[14] A. H. Mohammad Alizadeh et al., "ERCP Features and Outcome in Patients with Periampullary Duodenal Diverticulum," ISRN Gastroenterology, vol. 2013, pp. 1-5, 2013.

[15] G. Uomo, G. Manes, A. Ragozzino, A. Cavallera, and P. G. Rabitti, "Periampullary extraluminal duodenal diverticula and acute pancreatitis: An underestimated etiological association," American Journal of Gastroenterology, 1996.

[16] M. L. Silviera et al., "Complications related to endoscopic retrograde cholangiopancreatography: A comprehensive clinical review," Journal of Gastrointestinal and Liver Diseases. 2009.

[17] P. Katsinelos et al., "Impact of periampullary diverticula on the outcome and fluoroscopy time in endoscopic retrograde cholangiopancreatography," Hepatobiliary and Pancreatic Diseases International, 2013.

[18] J. Wen, T. Li, Y. Lu, L. K. Bie, and B. Gong, "Comparison of efficacy and safety of transpancreatic septotomy, needle-knife fistulotomy or both based on biliary cannulation unintentional pancreatic access and papillary morphology," Hepatobiliary and Pancreatic Diseases International, 2019.

[19] J. Halttunen et al., "Difficult cannulation as defined by a prospective study of the Scandinavian Association for Digestive Endoscopy (SADE) in 907 ERCPs," Scandinavian Journal of Gastroenterology, vol. 49, no. 6, pp. 752-758, 2014.

[20] T. C. K. Tham and M. Kelly, "Association of periampullary duodenal diverticula with bile duct stones and with technical success of endoscopic retrograde cholangiopancreatography," Endoscopy, 2004.

[21] G. Novacek, M. Walgram, P. Bauer, R. Schöfl, A. Gangl, and R. Pötzi, "The relationship between juxtapapillary duodenal diverticula and biliary stone disease," European Journal of Gastroenterology and Hepatology, 1997.

[22] E. Christoforidis, I. Goulimaris, I. Kanellos, K. Tsalis, and I. Dadoukis, "The role of juxtapapillary duodenal diverticula in biliary stone disease," Gastrointestinal Endoscopy, 2002.

[23] M. Ilhan Yildirgan et al., "Periampullary diverticula causing pancreaticobiliary disease," Digestive Diseases and Sciences, 2004.

[24] C. Van Nieuwkoop, I. Boere, P. A. M. Rosekrans, and D. J. Bac, "Recurrent bacterial cholangitis due to a juxtapapillary diverticulum," European Journal of Gastroenterology and Hepatology, 2002. 
[25] C. J. Krones et al., "The rare epidemiologic coincidence of diverticular disease and advanced colonic neoplasia," International Journal of Colorectal Disease, 2006.

[26] M. M. Meurs-Szojda, J. S. T. S. Droste, D. J. Kuik, C. J. J. Mulder, and R. J. F. FeltBersma, "Diverticulosis and diverticulitis form no risk for polyps and colorectal neoplasia in 4,241 colonoscopies," International Journal of Colorectal Disease, 2008.

[27] J. Jablonsky, "Efficiency analysis in multi-period systems: an application to performance evaluation in Czech higher education," Central European Journal of Operations Research, vol. 24, no. 2, pp. 283-296, Jun. 2016.

[28] D. S. Myung et al., "Cap-assisted ERCP in patients with difficult cannulation due to periampullary diverticulum,” Endoscopy, 2014.

[29] M. S. Cappell, E. Mogrovejo, P. Manickam, and M. Batke, "Endoclips to Facilitate Cannulation and Sphincterotomy During ERCP in a Patient with an Ampulla Within a Large Duodenal Diverticulum: Case Report and Literature Review," Digestive Diseases and Sciences, 2014.

[30] U. Saritas, Y. Ustundag, and F. Harmandar, "Precut sphincterotomy: A reliable salvage for difficult biliary cannulation," World Journal of Gastroenterology, vol. 19, no. 1, pp. 17, 2013.

[31] D. Xinopoulos et al., "Pancreatic duct guidewire placement for biliary cannulation in a single-session therapeutic ERCP," World Journal of Gastroenterology, vol. 17, no. 15, pp. 1989-1995, 2011.

[32] A. Rajnakova, P. M. Y. Goh, S. S. Ngoi, and S. G. Lim, "ERCP in patients with periampullary diverticulum," Hepato-Gastroenterology, 2003. 